\title{
CTR prediction for optimizing the negotiation of internet advertising campaigns
}

\author{
Autores \\ Jesús Silva, Jesús Vargas, Darwin Rizzo Vergara, Guillermo Araya, César Rosado, \\ Omar Bonerge Pineda Lezama, Benjamín Quintero
}

\section{Abstract}

Web advertising campaigns have the particularity that allow to measure the performance of campaigns based on different metrics, among which are the cost per thousand impressions (CPM-Cost Per mille), cost per click (CPC) and the click-to-print ratio (CTR-Click Through Ratio). For this reason, each ad has a specific objective based on these indicators which aim to distribute the purchase of advertising space on the Internet in the best possible way in order to have a better return on investment based on these metrics. The costs incurred in the development of its services is significant and the objectives of the campaigns are not always achieved because it assumes the variability of Internet user behavior. This project consists of proposing a regression model based on the historical data of the companies providing the programmatic purchasing service, in order to optimize negotiations on performance metrics in advertising campaigns with advertisers.

Palabras clave

Smart cities, Wireless sensor networks, Internet of things, Wireless nodes, Communication architecture. 